\title{
The Efficacy and Safety of
} Yokukansankachimpihange for Treating Behavioral and Psychological Symptoms of Dementia in Patients with Alzheimer's Disease: An Open-Label Pilot Study

\author{
Ryutaro Arita1, Tetsuhiro Yoshino', Miwako Ohgishi', Takuya Hamaguchi', Yuko Horiba1, \\ Kaori Sawai', Kei Funaki², Hajime Tabuchi2, Mizuki Oka², Takahito Yoshizaki ${ }^{3}$, \\ Kenji Watanabe1,4, Masaru Mimura1,2
}

\footnotetext{
${ }^{1}$ Center for Kampo Medicine, School of Medicine, Keio University, Tokyo, Japan

${ }^{2}$ Department of Neuropsychiatry, School of Medicine, Keio University, Tokyo, Japan

${ }^{3}$ Department of Neurology, School of Medicine, Keio University, Tokyo, Japan

${ }^{4}$ Faculty of Environmental and Information Study, Keio University, Fujisawa, Japan

Email: tarikun@keio.jp
}

\begin{abstract}
How to cite this paper: Arita, R., Yoshino, T., Ohgishi, M., Hamaguchi, T., Horiba, Y., Sawai, K., Funaki, K., Tabuchi, H., Oka, M., Yoshizaki, T., Watanabe, K. and Mimura, M. (2018) The Efficacy and Safety of Yokukansankachimpihange for Treating Behavioral and Psychological Symptoms of Dementia in Patients with Alzheimer's Disease: An Open-Label Pilot Study. $A d$ vances in Alzheimer's Disease, 7, 141-152. https://doi.org/10.4236/aad.2018.74010
\end{abstract}

Received: October 5, 2018

Accepted: December 7, 2018

Published: December 10, 2018

Copyright $\odot 2018$ by authors and Scientific Research Publishing Inc. This work is licensed under the Creative Commons Attribution International License (CC BY 4.0).

http://creativecommons.org/licenses/by/4.0/

c) (i) Open Access

\begin{abstract}
Previous clinical trials have demonstrated the efficacy of yokukansan, a traditional Japanese medicine, for the treatment of behavioral and psychological symptoms of dementia (BPSD). However, less evidence is available for the treatment of BPSD with yokukansankachimpihange (YKSCH), which consists of yokukansan and two additional herbal ingredients. The present study was conducted to investigate the efficacy and safety of YKSCH for treating BPSD in patients with Alzheimer's disease (AD). We enrolled outpatients with mild-to-moderate AD who exhibited BPSD and obtained a Neuropsychiatric Inventory (NPI) score of $>3$ including subscale scores for "agitation", "anxiety", "irritability", and "sleep and night-time behavior change". A daily YKSCH dose of $7.5 \mathrm{~g}$ was administered for 12 weeks with concomitant administration of anti-dementia medication. BPSD was evaluated using the NPI at baseline and every 4 weeks during the intervention. We also examined apathy using the Japanese translation of the Apathy Scale, the short version of the Japanese version of the Zarit Caregiver Burden Interview, and the Modified Crichton Rating Scale for Predicting Activities of Daily Living. Cognitive dysfunction was evaluated using the Mini Mental State Examination and the $\mathrm{AD}$ Assessment Scale-Cognitive (Japanese version). Five participants were enrolled. The NPI total score tended to decrease between the baseline and
\end{abstract}


8-week evaluations during the YKSCH intervention (Wilcoxon signed rank test, $\mathrm{P}=0.063$ ). In terms of the NPI subscale scores, "apathy", "agitation", "delusions", and "sleep and night-time behavior change" decreased after the intervention in those who exhibited each symptom at baseline. There were no significant differences in the other scores examined. No serious adverse events were observed. YKSCH could ameliorate BPSD in patients with mild-to-moderate $\mathrm{AD}$ with agitation, anxiety, irritability, and sleep and night-time behavior change, and it was well-tolerated.

\section{Keywords}

Alzheimer's Disease, Behavioral and Psychological Symptoms of Dementia, Yokukansankachimpihange, Kampo Medicine, Apathy, Neuropsychiatric Inventory

\section{Introduction}

Behavioral and psychological symptoms of dementia (BPSD) constitute the major symptoms of dementia, in addition to cognitive impairment. Approximately $80 \%$ of patients with Alzheimer's disease (AD) exhibited at least one of the BPSD [1]. The clinical phenotype of BPSD differs not only on a patient by patient basis, but also in the disease progression of each patient. BPSD become a mental and physical burden for caregivers and is a major reason for early institutionalization of patients with dementia, and thereby increases the cost of clinical care [2] [3] [4].

Yokukansan, a traditional Japanese medicine (Kampo medicine), has been reported to ameliorate BPSD, as assessed using the Neuropsychiatric Inventory (NPI) in four randomized control trials (RCTs) [5] [6] [7] [8]. A meta-analysis including these trials demonstrated the efficacy of yokukansan for treating BPSD, particularly for treating delusions, hallucinations, and agitation [9]. However, a subsequent randomized double-blind placebo-controlled trial of yokukansan for treating BPSD in AD indicated no significant efficacy. Nevertheless, in the subgroup with lower cognitive function, a greater decrease in agitation score was found in the yokukansan treatment group than the control group [10]. Yokukansan is currently listed in the practice guidelines for the treatment of dementia in Japan [11].

Yokukansankachimpihange (YKSCH) is comprised of yokukansan with Citrus unshiu peel (chimpi, peel of Citrus unshiu) and Pinellia tuber (hange, tuber of Pinellia ternata). YKSCH is used for patients with digestive dysfunction and nausea, along with irritation and agitation, which is the indication of yokukansan in traditional theory. YKSCH has also been reported to decrease the BPSD of patients with dementia [12] [13] [14] [15]. However, in these studies, BPSD was evaluated using scales other than the NPI. It is therefore unclear whether YKSCH is effective in treating BPSD as assessed using the NPI, which is a stan- 
dard and reliable scale for evaluating BPSD. The purpose of this study was to examine the efficacy and safety of YKSCH for treating the BPSD in patients with $\mathrm{AD}$ as assessed using the NPI.

\section{Methods}

\subsection{Study Design}

The present study was a prospective, single-arm, exploratory clinical study to examine the efficacy and safety of YKSCH for treating BPSD in AD in an outpatient clinical setting. This study was carried out in compliance with the Helsinki Declaration and study protocol, and it was approved by the institutional review board of Keio University School of Medicine and registered with the University Hospital Medical Information Network clinical trial registry (UMIN 000018369). Written informed consent to participate in this study was obtained from all patients or their substitute consent provider, as well as their caregivers.

\subsection{Participants}

Participants were recruited from either the memory clinic or the Department of Neuropsychiatry at Keio University Hospital from July 2015 to December 2016. Patients who met all of the following entry criteria were registered in this study: 1) Aged 65 - 89 years; 2) Probable $\mathrm{AD}$ according to the criteria of the National Institute of Neurological and Communicative Disorders and Stroke and AD and Related Disorders Association [16]; 3) Concomitant BPSD with an NPI score [17] >3 including subscale scores for "agitation", "anxiety", "irritability", and "sleep and night-time behavior change" of the NPI; 4) mild-to-moderate cognitive impairment based on a Mini Mental State Examination (MMSE) score [18] of 10 - 26 points; 5) Prescribed any cholinesterase inhibitor (ChEI), memantine, or N-methyl-D-aspartate (NMDA) receptor antagonist, for a minimum of 3 months without a change in dosage in the 4 weeks prior to entry.

We excluded patients with episodes of major depression, bipolar disorder, schizophrenia, alcoholism, or drug dependence; with concomitant use of antipsychotic agents; or with a change in their prescribed dosage of ChEI, memantine, NMDA receptor antagonist, antidepressants, anxiolytic agents, Ginkgo Biloba extract, ferulic acid, or any Kampo formula in the 4 weeks prior to starting the study treatment.

\subsection{Interventions}

All patients received $2.5 \mathrm{~g}$ of YKSCH extract granules prepared for ethical use (TJ-83, Tsumura \& Co.) 3 times daily for 12 weeks. The extract is produced via the process of decoction, concentration, drying, and addition of an excipient, and the daily dose $(7.5 \mathrm{~g})$ contained nine crude medicinal botanical substances as follows; $5 \mathrm{~g}$ of Pinellia tuber, $4 \mathrm{~g}$ of Atractylodes lancea rhizome, $4 \mathrm{~g}$ of Poria sclerotium, $3 \mathrm{~g}$ of Cnidium rhizome, $3 \mathrm{~g}$ of Uncaria hook, $3 \mathrm{~g}$ of Citrus unshiu peel, $3 \mathrm{~g}$ of Japanese Angelica root, $2 \mathrm{~g}$ of Bupleurum root, and $1.5 \mathrm{~g}$ of Glycyr- 
rhiza root [19]. The daily YKSCH dose could be decreased to $5.0 \mathrm{~g}$ a day, depending on the weight, age, and psychiatric symptoms of the participants. During the trial, other medications or medical services were adjourned.

\subsection{Outcome}

The primary outcome measure was the NPI total score, which contains 10 items (i.e., "delusions", "hallucinations", "agitation”, “depression”, "anxiety”, “euphoria", "apathy", "disinhibition", "irritability", and "aberrant motor behavior"). Two additional behavioral changes were also assessed as the NPI subscore: "sleep and night-time behavior change" and "appetite and eating change" [17]. The NPI score has been widely used in previous RCTs of yokukansan for treating BPSD [5] [6] [7] [8]. The higher score of the NPI means more severity of the BPSD. The secondary outcome measures were the NPI subscale scores, apathy score in the Japanese translation of the Apathy Scale (AS-J) [20] [21], the short version of the Japanese version of the Zarit Caregiver Burden Interview (J-ZBI_8) [22], and the Modified Crichton Rating Scale for Predicting Activities of Daily Living (mCRS) [23]. At baseline and at 4, 8, and 12 weeks during the intervention, the NPI, AS, J-ZBI_8, and mCRS scores were measured. Cognitive dysfunction was assessed using the MMSE and the AD Assessment Scale-cognitive component-Japanese version (ADAS-J cog) [24] by trained psychologists at baseline and after the 12-week intervention.

The safety of YKSCH was assessed based on blood pressure, pulse, physical examinations, hematological tests, and biochemical tests at every visit.

\subsection{Statistical Analysis}

For comparison of the variables at different time points, a Friedman repeated measures ANOVA was used. For comparison of the variables between the baseline and at 4,8 , and 12 weeks during the intervention, the Wilcoxon signed rank test was used. A P-value of $<0.05$ was considered to indicate a statistically significant difference. No adjustments of multiple comparisons were made.

\section{Results}

Five patients met the entry criteria, and all of them participated in the study. The demographic background information of the participants is provided in Table 1. The median age of the participants was 80 years, and two females were included. All participants had been prescribed ChEI and/or memantine. One participant did not complete ADAS-J cog at the baseline evaluation.

The NPI total score and component subscale scores are provided in Table 2. Compared to the score at baseline, the NPI total score of all participants decreased after 8 weeks, but the difference was not statistically significant (Wilcoxon signed rank test, $\mathrm{P}=0.063$ ) (Figure $1(\mathrm{a})$ ).

In the comparison of the NPI subscale scores, four participants obtained "apathy" scores at baseline and all of the scores decreased, particularly at 4 and 8 
Table 1. The demographic background of the participants.

\begin{tabular}{|c|c|c|c|c|c|}
\hline Paricipant & 1 & 2 & 3 & 4 & 5 \\
\hline Age (years) & 87 & 79 & 84 & 75 & 80 \\
\hline Sex & Male & Female & Female & Female & Male \\
\hline Body Mass Index & 17.9 & 21.9 & 22 & 24.5 & 25.5 \\
\hline $\begin{array}{c}\text { Duration of } \\
\text { dementia (months) }\end{array}$ & 35 & 21 & 40 & 23 & 94 \\
\hline $\begin{array}{l}\text { Duration of BPSD } \\
\text { (months) }\end{array}$ & 39 & 6 & 5 & 23 & 94 \\
\hline $\begin{array}{l}\text { Medications for } \\
\text { Alzheimer's } \\
\text { Disease }\end{array}$ & $\begin{array}{l}\text { Galantamine } \\
24 \mathrm{mg} / \text { day }\end{array}$ & $\begin{array}{c}\text { Galantamine } \\
24 \mathrm{mg} / \text { day, } \\
\text { memantine } \\
20 \mathrm{mg} / \text { day }\end{array}$ & $\begin{array}{l}\text { Donepezil } \\
5 \mathrm{mg} / \text { day }\end{array}$ & $\begin{array}{l}\text { Donepezil } \\
5 \mathrm{mg} / \text { day }\end{array}$ & $\begin{array}{l}\text { Memantine } \\
20 \mathrm{mg} / \text { day }\end{array}$ \\
\hline NPI & 16 & 17 & 5 & 14 & 22 \\
\hline MMSE & 26 & 20 & 23 & 20 & 14 \\
\hline ADAS-J $\operatorname{cog}$ & 14.67 & $\dagger$ & 24.66 & 17.67 & 23 \\
\hline AS & 31 & 19 & 14 & 21 & 42 \\
\hline J-ZBI_8 & 7 & 11 & 4 & 8 & 19 \\
\hline mCRS & 8 & 15 & 4 & 16 & 37 \\
\hline
\end{tabular}

$\dagger$ Not completed. NPI, Neuropsychiatric Inventory; MMSE, Mini-Mental State Examination; ADAS-J cog, Alzheimer's Disease Assessment Scale-cognitive component-Japanese version; AS, Apathy Score in Japanese translation; J-ZBI_8, the short version of the Japanese version of the Zarit Caregiver Burden Interview; mCRS, the Modified Crichton Rating Scale for Predicting Activities of Daily Living.

Table 2. Changes in neuropsychiatric inventory scores during the trial.

\begin{tabular}{|c|c|c|c|c|c|}
\hline $\mathrm{n}=5$ & baseline & 4 weeks & 8 weeks & 12 weeks & $\mathrm{P}$ value \\
\hline Total score & $14.8 \pm 6.2$ & $10.2 \pm 8.2$ & $4.8 \pm 2.5$ & $9 \pm 7.4$ & 0.11 \\
\hline \multicolumn{6}{|l|}{ Subscale score } \\
\hline Delusions & $1.2 \pm 2.7$ & $0.6 \pm 0.9$ & $0 \pm 0$ & $0.2 \pm 0.4$ & 0.51 \\
\hline Hallucinations & $0.2 \pm 0.4$ & $1.0 \pm 1.2$ & $0.2 \pm 0.4$ & $0.4 \pm 0.9$ & 0.3 \\
\hline Agitation/Agression & $1.4 \pm 1.9$ & $0.6 \pm 0.9$ & $0.2 \pm 0.4$ & $0 \pm 0$ & 0.39 \\
\hline Dysphoria/Depression & $1.0 \pm 1.2$ & $1.2 \pm 2.7$ & $0.6 \pm 0.5$ & $0.2 \pm 0.4$ & 0.48 \\
\hline Anxiety & $3.0 \pm 3.3$ & $3.4 \pm 4.2$ & $0.6 \pm 0.5$ & $3.0 \pm 5.1$ & 0.24 \\
\hline Euphoria & $0 \pm 0$ & $0.8 \pm 1.8$ & $0 \pm 0$ & $0 \pm 0$ & 0.39 \\
\hline Apathy & $6.2 \pm 4.7$ & $2.0 \pm 3.4$ & $1.0 \pm 1.7$ & $3.8 \pm 4.0$ & $0.038^{*}$ \\
\hline Disinhibition & $1.0 \pm 1.7$ & $0 \pm 0$ & $0 \pm 0$ & $0.2 \pm 0.4$ & 0.3 \\
\hline Irritability & $0.8 \pm 1.3$ & $0.6 \pm 0.9$ & $1.4 \pm 2.6$ & $0 \pm 0$ & 0.32 \\
\hline $\begin{array}{c}\text { Abberant Motor } \\
\text { Behavior }\end{array}$ & $0 \pm 0$ & $0 \pm 0$ & $0.8 \pm 1.1$ & $1.2 \pm 1.6$ & 0.11 \\
\hline $\begin{array}{c}\text { Sleep and Night-Time } \\
\text { Behavior Change }\end{array}$ & $2.8 \pm 3.9$ & $1.6 \pm 3.6$ & $1.6 \pm 3.6$ & $0.8 \pm 1.8$ & 0.26 \\
\hline $\begin{array}{l}\text { Appetite and } \\
\text { Eating change }\end{array}$ & $2.6 \pm 1.9$ & $1.6 \pm 2.2$ & $1.0 \pm 1.7$ & $1.6 \pm 3.6$ & 0.33 \\
\hline
\end{tabular}

Mean $\pm \mathrm{SD},{ }^{\star} \mathrm{P}<0.05$ analyzed by Friedman test. 


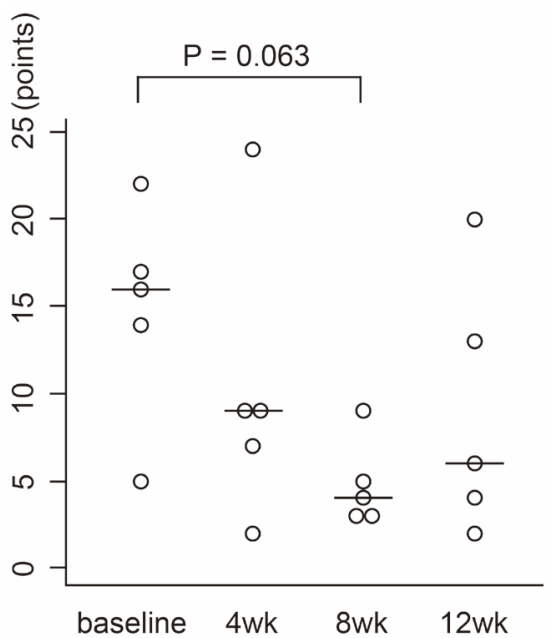

(a)

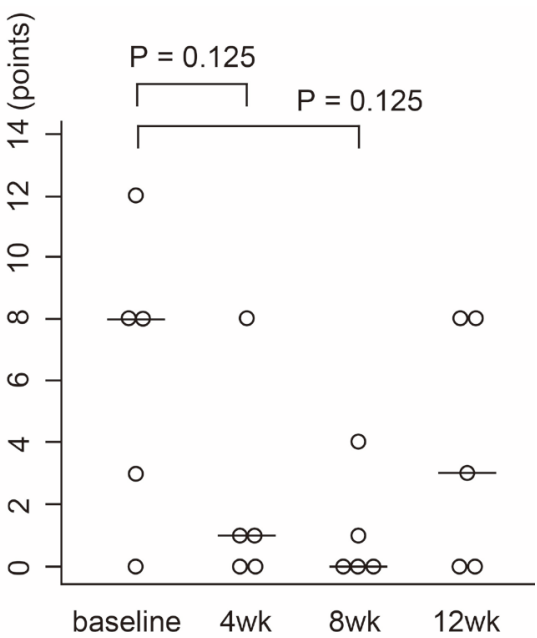

(b)

Figure 1. Changes in Neuropsychiatric Inventory (NPI) total scores (a), and apathy subscale score (b) during the trial. Circles are the scores of the participants $(n=5)$, and the horizontal lines are the median scores. Data were analyzed by Wilcoxon signed rank test. (a) NPI total score; (b) NPI apathy score.

weeks during the YKSCH intervention. There was a significant difference in the "apathy" score (Friedman test, $\mathrm{P}=0.038$ ), but no significant decrease was found between the scores at baseline and at each observation period (Figure 1(b), Table 2). The "agitation", "delusions", and "sleep and night-time behavior change" scores also decreased after administration of YKSCH in the participants who exhibited each symptom at baseline, but there were no significant differences between the scores at baseline and at each observation period.

No significant differences were observed in the AS-J, J-ZBI_8, mCRS, MMSE and ADAS-J cog scores during the YKSCH intervention.

One participant exhibited weight loss, and mild leg edema and hypertension were observed in one participant, both which were spontaneously resolved. These adverse events were not considered to be due to YKSCH administration.

\section{Discussion}

The results of the present study demonstrated that YKSCH has the tendency to alleviate BPSD as assessed using the NPI in patients with AD after 8-week administration, and that $\mathrm{YKSCH}$ is a well-tolerated treatment option. Previous trials reported that YKSCH significantly improved AD patients' BPSD, as assessed by the Behavioral Pathology in AD Rating Scale [13] [14]. Thus, YKSCH may have a therapeutic effect on the BPSD in patients with $\mathrm{AD}$, regardless of assessment scale.

With regard to the subscale scores of the NPI, the "apathy", "agitation", "delusions", and "sleep and night-time behavior change" scores decreased after administration of YKSCH in the participants who exhibited each symptom at baseline (Table 2). Although previous studies reported that $\mathrm{YKSCH}$ was effective for 
treating agitation, delusions, or sleep and night-time behavior change in patients with dementia, these studies did not evaluate apathy, simply because the evaluation scales used in these studies did not measure apathy [12] [13] [14].

To our knowledge, this is the first study to demonstrate the possibility of alleviating apathy with administration of $\mathrm{YKSCH}$. On the other hand, the AS-J, another scale for evaluating apathy, revealed no tendency towards improvement. In addition to the statistical power, the differences in the questionnaire items between the NPI apathy subscale and the AS-J might have produced different results. Apathy in AD is defined as loss of interest and motivation in daily activities in the absence of depression or other mood changes [25]. Apathy is one of the most frequent BPSD in AD [26], and is associated with poorer quality of life [27], faster cognitive and functional decline [28], and greater caregiver burden [29] [30].

There is some evidence for the benefit of pharmacotherapies for treating apathy in $\mathrm{AD}$ patients. Methylphenidate, specifically in the form of sustained release tablets, is a psycho-stimulant that acts on the dopaminergic brain reward system and was a candidate drug for the treatment of apathy. Two RCTs have reported the efficacy of methylphenidate for treating apathy in AD patients [31] [32]. However, severe adverse effects were observed such as delusions, hallucinations, and restlessness. Therefore, the safety of methylphenidate treatment may be an issue, particularly in elderly patients with dementia. However, Feldman et al. reported in a post hoc analysis of a placebo-controlled RCT that apathy in patients with more severe AD was significantly improved after 24-week treatment of donepezil, as a secondary outcome [33]. Nonetheless, a meta-analysis revealed that pharmacological therapy using ChEI, memantine, and psycho-stimulants including methylphenidate had no significant effect on apathy [34].

It is unclear whether the positive effects of $\mathrm{YKSCH}$ are associated with dopamine function or apathy. Yokukansan was reported to partially improve the extracellular concentration of dopamine in the prefrontal cortices of aged rats [35]. Geissoschizine methyl ether, a common constituent of YKSCH and yokukansan, behaves as a partial agonist/antagonist at the dopamine $\mathrm{D} 2 \mathrm{~L}$ receptor [36]. With regard to the unique ingredients of $\mathrm{YKSCH}$, naringin, which is a flavonoid found in Citrus unshiu peel, was found to have a neuroprotective effect in the nigrostriatal dopaminergic projections in a Parkinson's disease model rodents [37] [38]. Further studies are needed to clarify how these ingredients work in the $\mathrm{AD}$ brain.

Various studies on Kampo medicine for the treatment of BPSD may indicate which Kampo medicine should be used according to the symptoms of each patientas follows. YKSCH may be effective for treating AD cases comprising both the "negative" (apathy) and "positive" (agitation and delusions) parts of BPSD. On the other hand, yokukansan is effective in patients predominantly presenting with "positive symptoms" such as delusions, hallucinations, and agitation. Ninjin'yoeito has been reported to be effective in treating anorexia and apathy in AD 
patients with frailty [39], and depression [40]. Therefore, ninjin'yoeito may be effective for treating the "negative symptoms". However, the quality of the clinical trials using YKSCH and ninjin'yoeito was low and these results were measured as secondary outcomes. Further trials with larger samples wherein the primary outcomes are specific symptoms of BPSD are warranted.

There were no significant changes in cognitive function before and after treatment with YKSCH. This result corresponded with previous research in dementia patients [12] [13].

Two participants experienced adverse events in this study, but we concluded that YKSCH did not cause these events. Weight loss in one participant was attributable to abnormal eating behavior; he could chew but not swallow prior to the intervention. This behavior was thought to be a BPSD, but it did not improve with YKSCH treatment. Leg edema and hypertension were observed in one participant, but these effects were mild and disappeared during the intervention.

This study has several limitations. First, the number of participants was very small, and a control group was not included in this study. Second, the caregivers of the participants were not controlled, and evaluation of the BPSD may have therefore varied according to their condition. Third, the degree of BPSD was relatively mild, since only outpatients of a university hospital were recruited. Fourth, the decrease in the BPSD did not continue throughout the intervention period. Large-scale, comparative trials in an inpatient setting are needed to resolve these problems.

\section{Conclusion}

This pilot study indicated that YKSCH could be a useful and safe option for treating BPSD including agitation, anxiety, irritability, and sleep and night-time behavior change in mild-to-moderate $\mathrm{AD}$ patients. This compound may also be beneficial for the treatment of apathy. To confirm the efficacy of $\mathrm{YKSCH}$, and RCTs recruiting more AD participants will be needed in the future.

\section{Acknowledgements}

The authors would like to thank T. Wake and M. Konishi for performing the psychological examinations.

\section{Conflicts of Interest}

The authors declare no conflicts of interest regarding the publication of this paper.

\section{Disclosure Statement}

This study was funded by Tsumura \& Co. (Tokyo, Japan). The sponsor of the study had no role in the study design, conduct of the study, data collection, data interpretation, or preparation of the report. Center for Kampo Medicine, Keio University School of Medicine receives donation toward scholarships from Kra- 
cie Pharmaceutical, Ltd.

\section{References}

[1] Yatawara, C., Hiu, S., Tan, L. and Kandiah, N. (2018) Neuropsychiatric Symptoms in South-East Asian Patients with Mild Cognitive Impairment and Dementia: Prevalence, Subtypes, and Risk Factors. International Journal of Geriatric Psychiatry, 33, 122-130. https://doi.org/10.1002/gps.4693

[2] Beeri, M.S., Werner, P., Davidson, M. and Noy, S. (2002) The Cost of Behavioral and Psychological Symptoms of Dementia (BPSD) in Community Dwelling Alzheimer's Disease Patients. International Journal of Geriatric Psychiatry, 17, 403-408. https://doi.org/10.1002/gps.490

[3] Kamiya, M., Sakurai, T., Ogama, N., Maki, Y. and Toba, K. (2014) Factors Associated with Increased Caregivers' Burden in Several Cognitive Stages of Alzheimer's disease. Geriatrics \& Gerontology International, 14, 45-55.

https://doi.org/10.1111/ggi.12260

[4] Steele, C., Rovner, B., Chase, G.A. and Folstein, M. (1990) Psychiatric Symptoms and Nursing Home Placement of Patients with Alzheimer's Disease. American Journal of Psychiatry, 147, 1049-1051. https://doi.org/10.1176/ajp.147.8.1049

[5] Iwasaki, K., Satoh-Nakagawa, T., Maruyama, M., Monma, Y., Nemoto, M., et al. (2005) A Randomized, Observer-Blind, Controlled Trial of the Traditional Chinese Medicine Yi-Gan San for Improvement of Behavioral and Psychological Symptoms and Activities of Daily Living in Dementia patients. Journal of Clinical Psychiatry, 66, 248-252. https://doi.org/10.4088/JCP.v66n0214

[6] Mizukami, K., Asada, T., Kinoshita, T., Tanaka, K., Sonohara, K., et al. (2009) A Randomized Cross-Over Study of a Traditional Japanese Medicine (Kampo), Yokukansan, in the Treatment of the Behavioral and Psychological Symptoms of Dementia. International Journal of Neuropsychopharmacology, 12, 191-199. https://doi.org/10.1017/S146114570800970X

[7] Monji, A., Takita, M., Samejima, T., Takaishi, T., Hashimoto, K., et al. (2009) Effect of Yokukansan on the Behavioral and Psychological Symptoms of Dementia in Elderly Patients with Alzheimer's Disease. Progress in Neuro-Psychopharmacology \& Biological Psychiatry, 33, 308-311. https://doi.org/10.1016/j.pnpbp.2008.12.008

[8] Okahara, K., Ishida, Y., Hayashi, Y., Inoue, T., Tsuruta, K., et al. (2010) Effects of Yokukansan on Behavioral and Psychological Symptoms of Dementia in Regular Treatment for Alzheimer's Disease. Progress in Neuro-Psychopharmacology \& Biological Psychiatry, 34, 532-536. https://doi.org/10.1016/j.pnpbp.2010.02.013

[9] Matsuda, Y., Kishi, T., Shibayama, H. and Iwata, N. (2013) Yokukansan in the Treatment of Behavioral and Psychological Symptoms of Dementia: A Systematic Review and Meta-Analysis of Randomized Controlled Trials. Human Psychopharmacology, 28, 80-86. https://doi.org/10.1002/hup.2286

[10] Furukawa, K., Tomita, N., Uematsu, D., Okahara, K., Shimada, H., et al. (2017) Randomized Double-Blind Placebo-Controlled Multicenter Trial of Yokukansan for Neuropsychiatric Symptoms in Alzheimer's Disease. Geriatrics \& Gerontology International, 17, 211-218. https://doi.org/10.1111/ggi.12696

[11] Japanese Society of Neurology (2017) Practice Guideline for the Treatment of Dementia 2017. Igaku-Shoin, Tokyo. (In Japanese)

[12] Magome, A. (2011) Effect of Yokukansankachimpihange on Dementia-Including the Point of View of Oriental Medicine. Psychiatry, 18, 108-114. (In Japanese with 
English Abstract)

[13] Katsumoto, E., Ishida, T., Kinoshita, K., Shimizu, M., Tsutsumi, T., et al. (2016) Efficacy and Safety of Yokukansankachimpihange on BPSD. Japanese Journal of Medicine and Pharmaceutical Science, 73, 846-853. (In Japanese with English Abstract)

[14] Miyazawa, J. (2009) Study of the Clinical Efficacy of Yokukansankachimpihange on Alzheimer's Disease. Psychiatry, 14, 535-542. (In Japanese with English Abstract)

[15] Fujita, N., Yoshida, M., Yomoda, S. and Itomura, M. (2013) Effect of Yokukansankachimpihange on Cognitive Ability, an Open Randomized Controlled Trial. Psychiatry, 23, 130-138. (In Japanese with English Abstract)

[16] McKhann, G., Drachman, D., Folstein, M., Katzman, R., Price, D. and Stadlan,E.M. (1984) Clinical Diagnosis of Alzheimer's Disease: Report of the NINCDS-ADRDA Work Group under the Auspices of Department of Health and Human Services Task Force on Alzheimer's Disease. Neurology, 34, 939.

https://doi.org/10.1212/WNL.34.7.939

[17] Cummings, J.L., Mega, M., Gray, K., Rosenberg-Thompson, S., Carusi, D.A. and Gornbein, J. (1994) The Neuropsychiatric Inventory: Comprehensive Assessment of Psychopathology in Dementia. Neurology, 44, 2308.

https://doi.org/10.1212/WNL.44.12.2308

[18] Folstein, M.F., Folstein, S.E. and McHugh, P.R. (1975) “Mini-Mental State": A Practical Method for Grading the Cognitive State of Patients for the Clinician. Journal of Psychiatric Research, 12, 189-198. https://doi.org/10.1016/0022-3956(75)90026-6

[19] Tsumura \& Co. (2013) Kampo-Preparation: TSUMURA Yokukansankachimpihange Extract Granules for Ethical Use. 5th Version, Tsumura \& Co., Tokyo.

[20] Starkstein, S.E., Mayberg, H.S., Preziosi, T.J., Andrezejewski, P., Leiguarda, R., et al. (2006) Reliability, Validity, and Clinical Correlates of Apathy in Parkinson's Disease. The Journal of Neuropsychiatry and Clinical Neurosciences, 4, 134-139. https://doi.org/10.1176/jnp.4.2.134

[21] Okada, K., Kobayashi, S., Yamagata, S., Takahashi, K. and Yamaguchi, S. (1997) Poststroke Apathy and Regional Cerebral Blood Flow. Stroke, 28, 2437-2441. https://doi.org/10.1161/01.STR.28.12.2437

[22] Arai, Y., Tamiya, N. and Yano, E. (2003) The Short Version of the Japanese Version of the Zarit Caregiver Burden Interview (J-ZBI_8): Its Reliability and Validity. The Japan Geriatrics Society, 40, 497-503. (In Japanese with English Abstract)

[23] Hasegawa, K., Honma, A., Takeda, M., Udaka, F., Imai, Y., et al. (2003) Evaluating the Family or Caregiver Impression of Donepezil on Alzheimer's Disease. Does Donepezil Help the Communication between Patients and Their Family? Geriatric Medicine, 41, 733-743. (In Japanese)

[24] Rosen, W.G., Mohs, R.C. and Davis, K.L. (2006) A New Rating Scale for Alzheimer's Disease. The American Journal of Psychiatry, 141, 1356-1364. https://doi.org/10.1176/ajp.141.11.1356

[25] Marin, R.S. (2006) Apathy: A Neuropsychiatric Syndrome. The Journal of Neuropsychiatry and Clinical Neurosciences, 3, 243-254. https://doi.org/10.1176/jnp.3.3.243

[26] Starkstein, S.E., Petracca, G., Chemerinski, E. and Kremer, J. (2001) Syndromic Validity of Apathy in Alzheimer's Disease. American Journal of Psychiatry, 158, 872-877. https://doi.org/10.1176/appi.ajp.158.6.872

[27] Hurt, C., Bhattacharyya, S., Burns, A., Camus, V., Liperoti, R., et al. (2008) Patient 
and Caregiver Perspectives of Quality of Life in Dementia: An Investigation of the Relationship to Behavioral and Psychological Symptoms in Dementia. Dementia and Geriatric Cognitive Disorders, 26, 138-146. https://doi.org/10.1159/000149584

[28] Starkstein, S.E., Jorge, R., Mizrahi, R. and Robinson, R.G. (2006) A Prospective Longitudinal Study of Apathy in Alzheimer's Disease. Journal of Neurology, Neurosurgery, and Psychiatry, 77, 8-11. https://doi.org/10.1136/jnnp.2005.069575

[29] Vilalta-Franch, J., Calvo-Perxas, L., Garre-Olmo, J., Turro-Garriga, O. and Lopez-Pousa, S. (2013) Apathy Syndrome in Alzheimer's Disease Epidemiology: Prevalence, Incidence, Persistence, and Risk and Mortality Factors. Journal of Alzheimer's Disease, 33, 535-543. https://doi.org/10.3233/JAD-2012-120913

[30] Dauphinot, V., Delphin-Combe, F., Mouchoux, C., Dorey, A., Bathsavanis, A., et al. (2015) Risk Factors of Caregiver Burden among Patients with Alzheimer's Disease or Related Disorders: A Cross-Sectional Study. Journal of Alzheimer's Disease, 44, 907-916. https://doi.org/10.3233/JAD-142337

[31] Rosenberg, P.B., Lanctot, K.L., Drye, L.T., Herrmann, N., Scherer, R.W., et al. (2013) Safety and Efficacy of Methylphenidate for Apathy in Alzheimer's Disease: A Randomized, Placebo-Controlled Trial. Journal of Clinical Psychiatry, 74, 810-816. https://doi.org/10.4088/JCP.12m08099

[32] Herrmann, N., Rothenburg, L.S., Black, S.E., Ryan, M., Liu, B.A., et al. (2008) Methylphenidate for the Treatment of Apathy in Alzheimer Disease: Prediction of Response Using Dextroamphetamine Challenge. Journal of Clinical Psychopharmacology, 28, 296-301. https://doi.org/10.1097/JCP.0b013e318172b479

[33] Feldman, H., Gauthier, S., Hecker, J., Vellas, B., Xu, Y., et al. (2005) Efficacy and Safety of Donepezil in Patients with More Severe Alzheimer's Disease: A Subgroup Analysis from a Randomized, Placebo-Controlled Trial. International Journal of Geriatric Psychiatry, 20, 559-569. https://doi.org/10.1002/gps.1325

[34] Sepehry, A.A., Sarai. M. and Hsiung, G.R. (2017) Pharmacological Therapy for Apathy in Alzheimer's Disease: A Systematic Review and Meta-Analysis. Canadian Journal of Neurological Sciences, 44, 267-275. https://doi.org/10.1017/cjn.2016.426

[35] Mizoguchi, K., Tanaka, Y. and Tabira, T. (2010) Anxiolytic Effect of a Herbal Medicine, Yokukansan, in Aged Rats: Involvement of Serotonergic and Dopaminergic Transmissions in the Prefrontal Cortex. Journal of Ethnopharmacology, 127, 70-76. https://doi.org/10.1016/j.jep.2009.09.048

[36] Ueda, T., Ugawa, S., Ishida, Y. and Shimada, S. (2011) Geissoschizine Methyl Ether has Third-Generation Antipsychotic-Like Actions at the Dopamine and Serotonin Receptors. European Journal of Pharmacology, 671, 79-86. https://doi.org/10.1016/j.ejphar.2011.09.007

[37] Jung, U.J., Leem, E. and Kim, S.R. (2014) Naringin: A Protector of the Nigrostriatal Dopaminergic Projection. Experimental Neurology, 23, 124-129.

[38] Kim, H.D., Jeong, K.H., Jung, U.J. and Kim, S.R. (2016) Naringin Treatment Induces Neuroprotective Effects in a Mouse Model of Parkinson's Disease in Vivo, but Not Enough to Restore the Lesioned Dopaminergic System. The Journal of Nutritional Biochemistry, 28, 140-146. https://doi.org/10.1016/j.jnutbio.2015.10.013

[39] Ohsawa, M., Tanaka, Y., Ehara, Y., Makita, S. and Onaka, K. (2017) A Possibility of Simultaneous Treatment with the Multicomponent Drug, Ninjin'yoeito, for Anorexia, Apathy, and Cognitive Dysfunction in Frail Alzheimer's Disease Patients: An Open-Label Pilot Study. Journal of Alzheimer's Disease Reports, 1, 229-235. https://doi.org/10.3233/ADR-170026 
[40] Kudoh, C., Arita, R., Honda, M., Kishi, T., Komatsu, Y., et al. (2016) Effect of Ninjin'yoeito, a Kampo (Traditional Japanese) Medicine, on Cognitive Impairment and Depression in Patients with Alzheimer's Disease: 2 Years of Observation. Psychogeriatrics, 16, 85-92. https://doi.org/10.1111/psyg.12125 